Jari Lavonen is a Professor of Physics and Chemistry Education at the Department of Teacher Education, University of Helsinki, Finland. His research area is on the use of Information and Communication Technology in science education.

Heidi Krzywacki works as a university lecturer and researcher in mathematics education at the Department of Teacher Education, University of Helsinki, Finland. Her research is on the use of information and communication technology in school, especially assessment in science and mathematics education.

Laura Koistinen, PhD student, works at the Department of Teacher Education, University of Helsinki, Finland. Her research is on the use of technology in education and school assessment from the teachers' perspective.

Manuela Welzel-Breuer is a Professor for Physics and Physics Education at the University of Education Heidelberg, Germany. Her research is in the fields of elementary and secondary science education, the use of communication technology in science classes, and science education for street children.

Roger Erb is a Professor for Physics Education at the Goethe-University Frankfurt, Germany. His research is on scientific thinking of learners when designing and running experiments or computer simulation of experiments.

JARI LAVONEN

Department of Teacher Education, University of Helsinki, Finland

HEIDI KRZYWACKI

Department of Teacher Education, University of Helsinki, Finland

LAURA KOISTINEN

Department of Teacher Education, University of Helsinki, Finland

MANUELA WELZEL-BREUER

University of Education Heidelberg, Germany

ROGER ERB

Goethe-Universität, Germany

\title{
In-service teacher education course module design focusing on usability of ICT applications in science education
}

\footnotetext{
Abstract

Teachers face challenges in adopting ICT applications for science teaching and learning. An in-service teacher education course module addressing the needs of science teachers particularly was developed through a design-based research (DBR) project. The course module is designed to improve the readiness of teachers in choosing ICT applications for science education and taking the technical and pedagogical usability of the application into account. An international survey showed that clarifying the needs and constraints of using ICT applications in science education as well as introducing and discussing both technical and pedagogical usability with the teachers was important. Moreover, a theoretical analysis of the usability of ICT applications offers various views on meaningful learning and motivational aspects of science teaching and learning. In this paper, we report what we learned from the experience of designing the course module, which is described and discussed in terms of the outcomes of both the theoretical and empirical problem analysis.
} 


\section{INTRODUCTION}

The OECD (2006) has pointed out the increasing gap between the current use of information and communication technology (ICT) in teaching and learning at schools and the daily experiences that pupils have with ICT outside of school. Furthermore, governments and other stakeholders in OECD countries have dedicated large budgets to support the use of ICT in schools. Several paradoxes can be recognised in the research literature on the use of ICT in science education (e.g., Hayes, 2007, OECD, 2004; 2006):

- national level ICT-strategies and national curriculum guidelines for ICT use have been prepared over the last two decades in several countries, but the influence on the practice of teachers regarding the use of ICT in education seems to be slight;

- students have rich experience in using ICT outside the school context but not for learning at school;

- science teachers are quite skilful in using ICT, even if they are unable to make good use of their competence by applying ICT applications in their teaching;

- ICT is available at school, but science teachers' beliefs about teaching and learning, e.g., beliefs about good practice in school, do not support the educational use of technology;

- plenty of teaching and learning material, especially with a focus on using ICT in science education, already exists (Osborne \& Hennessy, 2003). However, science teachers are not experienced in using these materials effectively within regular classroom activities.

In general, there is broad agreement on the reasons why ICT applications should be integrated into science education and the advantages of its use in teaching and learning science. According to numerous studies, use of ICT in science education could support meaningful learning and student motivation (Osborne \& Hennessy, 2003). However, teachers do not rely on research-based evidence in identifying good practices, nor do they see the usefulness of ICT use in science education. Moreover, it is generally known that implementation of educational policy and reforms in science education is either very slow or tends to fail (Lavonen, Juuti, Aksela, \& Meisalo, 2006). Supporting science teachers in adopting the use of ICT as a part of their teaching and to appreciate the usefulness of ICT in the science classroom is thus a challenge.

The aim of this paper is to describe what we learned from our experience of designing a course module that aims at supporting teachers in adopting ICT in their science classrooms. The usefulness of ICT applications in science education and understanding different dimensions of usability of ICT applications are discussed through the course module. We claim that the various dimensions of usability could form criteria in selecting ICT applications and planning the use of ICT applications in science education. This paper draws from the experiences and data gathered in designing the course module as a part of the EU Comenius project 'Effective Use of Computer Aided Teaching and Learning in Science Education'. The project was carried out in collaboration with six European countries in 2008-2010.

\section{THE DESIGN-BASED RESEARCH APPROACH TO THE COURSE DESIGN}

We used the design-based research approach (DBR), a general and pragmatic framework for design, development, implementation and evaluation of learning activities, as a methodological framework for designing the course module, which is suggested as a solution for the discontinuity between educational research and praxis (Juuti \& Lavonen, 2006). DBR emphasises three aspects: (a) a design process is essentially iterative, starting from recognition of the need to change praxis, (b) it generates a widely usable artefact, like a learning activity, learning environment or model of how an ICT application could be used, (c) and it provides educational knowledge for more intelligible praxis (Bell, Hoadley, \& Linn, 2004). 
DBR is composed of the combination of theory development, the prescriptions of successful design processes and design solutions. The procedure contains four main phases: 1) needs assessment; 2) theoretical problem analysis and definition of the objectives for a design solution or artefact; 3) design and production of the artefact; and 4) evaluation of the artefact.

\section{Analysis of Needs}

In order to clarify the needs and constraints regarding the use of ICT applications in science education, an international survey within the six participating countries (Austria, Bulgaria, Finland, France, Germany, and Greece) was designed and carried out. The aim of the survey was to gain insights into the spectrum of possible conditions, needs and actual practices in using ICT in science classrooms. In addition, the information needed to construct a teacher education course approximating the conditions in school contexts in various European countries was gathered (see Welzel-Breuer et al., 2009).

Here, we highlight points in the data that are central in designing the course module in terms of the usability of ICT applications. According to the survey, the confidence and competence of a teacher using ICT in the classroom seem to be interconnected. The feeling of being a competent ICT user in science education was related to attitudes towards ICT use in general, i.e., the more confident the users regard themselves as, the more positive conceptions they have of the benefits and added value of use. According to the responses to the open questions of the survey, the potential to increase student interest and motivation in science learning, support student autonomy and active learning were seen as the most positive features of using ICT in the classroom. Furthermore, it is entirely natural that the teachers who view themselves as competent users let their students use ICT in the classroom more often.

The teachers expressed the need for support in choosing appropriate ICT applications and becoming aware of various aspects of using ICT in science teaching and learning. In addition to these pedagogical issues, the most negative aspects were related to technical issues such as problems with learnability.

\section{THEORETICAL PROBLEM ANALYSIS}

Theoretical problem analysis starts with a brief description of the different ways of using ICT in science teaching and learning. Secondly, we will take a quick look at an ICT adoption process use in science education. After the general review, we continue with particular attention to aspects of the usability and versatility of ICT applications in science teaching and learning. We have divided our theoretical analysis into two categories, technical and pedagogical usability, in order to clarify the meaning of the concept usability and how it could be used in the selection of ICT applications and planning their use.

\section{Various uses of ICT in science education}

We categorise the use of ICT application here into (A) tool applications or tool software and (B) use of ICT applications in learning (learning through ICT) according to the objective (cf. Webb, 2002). In the tool category (A), ICT is treated as a set of available software enabling students and teachers to accomplish their tasks more efficiently. Typical examples of tool software are related to course administration and office tools (text processing, spreadsheets, graphics, etc.).

Science teachers can use tool applications in several ways. In addition to those previously mentioned, teachers can prepare assignments, tests, and other resources for teaching and learning. An LCD projector can be used as a tool for presentations in several ways and be connected to a microscope, for example. Furthermore, an interactive whiteboard (White board, SMART Board) provides new perspectives for teaching and learning in promoting interaction and the dynamic use of ICT in the classroom. 
The main uses of ICT applications in learning science (B) can be divided into four categories depending on how its use supports learning:

(i) Computer-assisted learning (CAL) is any interaction between a student and a computer system designed to help the student to learn. CAL includes simulations (Applets on the Internet) and virtual-reality environments;

(ii) Computer-assisted research is the use of ICT as an aid in collecting and analysing in formation and data from various information sources, as well as reporting the outcomes. Computer-assisted research is typically conducted in small collaborative groups, ICT be ing used as an agent for interaction with the information source and especially at different stages of research. For example, the web browser is used for searching information and microcomputer-based laboratories (MBL) for data acquisition and data processing; (iii) Computer-assisted interaction: Open and distance learning (ODL) has evolved in a na tural way from using regular e-mail into using all available IT services adjusted to facilitate student learning fully. Thus, modern ODL solutions are based on a wide range of communication technologies, such as course management systems like Moodle, and twoway audio/video tele-conferencing. Nowadays, schools are more involved with ICT-based interaction channels;

(iv) The Web 2.o ideology or social media is increasingly implemented in science educa tion. Web 2.o is understood as a virtual learning environment where platforms like blogs, wikis, podcasting, videoblogs, and social networking tools like MySpace and Face book are used for educational purposes. These platforms can create an atmosphere for col laborative writing and sharing ideas for students and teachers (Alexander, 2006).

\section{Adoption of ICT use in science education}

The aim of the course module designed in the project is to help science teachers to adopt ICT applications for educational purposes and to understand the dimensions of usability from the science education point of view. Here, we consider 'use of ICT application' as an educational innovation, analysing adoption within the framework of the adoption of innovation (Rogers, 2003). The adoption of innovation is defined as an individual's mental process starting with initial awareness of the innovation and resulting in the actual adoption of the innovation. The adoption process can be divided into several stages, as follows: awareness, interest, evaluation, trial, and adoption. Individuals who are members of the society adopting the innovation can be categorised into adopter categories: innovators, early adopters, early majority, late majority, and laggards (Rogers, 2003).

Fullan (2001) categorises the aspects that could have an effect on adoption in two general subsets. The first subset includes the properties of the innovation, in this case, the properties of the 'use of ICT applications' (e.g., differential use, usability of applications, and ease of use). However, the nature of this innovation is complex. For example, Watson (2001) argues that adoption requires changes in teaching style, learning approaches, and access to information. The second subset according to Fullan (2001) comprises local characteristics, such as the pedagogical orientation of the science teachers, and the nature of collaboration and reflection between teachers and their beliefs about the usability of ICT applications. In addition, the sense of limited time resources, especially a need for additional time for experimenting with ICT applications, the availability of technical and pedagogical support, adequate financial support, support for professional development as well as the nature of development influences ICT use. Furthermore, some external factors such as national ICT strategy can also influence the adoption of the innovation. Moreover, how ICT use in science education is located in the national curriculum as well as how this view has been realised in learning materials like textbooks and laboratory manuals have an influence on the adoption of the innovation (Osborne \& Hennessy, 2003). The use of ICT in science education should be planned and developed based on the science curriculum and therefore integrated into teaching and learning science, not added onto it (McFarlane \& Sakellariou, 2002). 


\section{Usability of ICT applications in science education}

The perceived usefulness of an ICT application, also referred to as an artefact, is evident in whether the its use achieves the intended goals. Usefulness can be divided into the sub-attributes of utility and usability based on their specified needs and goals. Nielsen (1993) describes utility as the number of features needed to reach the required goals and usability as the user's ability to use these features, i.e., a kind of measure of the quality of the features. Therefore, 'utility' answers the quantitative question of 'what' the user can do and 'usability' the qualitative question of 'how' the user can do it. Here we focus on the latter.

While planning a teaching situation, a teacher makes several decisions considering teaching approaches, learning materials and how to use ICT applications, i.e., usability. Consequently, it is possible to use various dimensions of the usability of ICT applications as criteria for the selection of an application in planning science teaching and learning. For example, according to Wang (2008), the usability of an educational artefact (or application) is important in its adoption and use.

The usability of an artefact indicates the extent to which people can employ the artefact in order to achieve a particular goal. In human-computer interaction and computer science, usability usually refers to the elegance and clarity with which the interaction with a computer programme or a web site is designed (Nielsen, 1993). Nielsen has approached the concept of usability from the perspective of the adoption and acceptability of an artefact. Along these lines, the usability of an artefact could be defined through five quality components:

- learnability, i.e., how easy it is for users to use a new artefact

- efficiency, i.e., how quickly users can perform tasks (organise learning activities) once they have learned to use the artefact

- memorability, i.e., how easily users can re-establish proficiency when returning to use the artefact.

- freedom from error, i.e., the fewer errors users make while using the artefact the better

- satisfaction, i.e., how pleasant the use of the artefact is or how easy it is to change elements or modify the artefact individually

Buzzetto-More (2007) and Nielsen (2000) relate such usability quality components to how an ICT application or a web environment is convenient, practicable, and usable for a user, referring to them as technical usability components. However, technical usability is defined in various ways. For example, Nokelainen (2005) lists accessibility, learnability and memorability, user control, support, graphical layout, reliability, consistency, efficiency, memory load and freedom from error as technical usability components. It is easier to start using an ICT application and adopt it if it is similar to other applications as it is in the 'office family' and is designed based on a metaphor, like a working table.

\section{Components of pedagogical usability}

In discussing teaching and learning, the pedagogical aspects of usability should be considered alongside the technical aspects. Squires and Preece (1999) propose the idea of a usability heuristics with a socio-constructivist learning perspective allowing for the integration of technical usability as well as learning aspects (see also Tergan, 1998). Hadjerrouit (2010) relates the concept of pedagogical usability to learning utility. Nokelainen (2005) approaches pedagogical usability through a theoretical analysis of meaningful learning, then validating the developed model through Bayesian dependency modeling and reliability analysis.

Here, we approach the pedagogical usability of an ICT application by analysing the kind of learning and development of motivation the use of the ICT application could create. These aspects seem to be 
important from the point of view of needs analysis. To conclude, the concept of usability should be introduced to teachers not only through technical aspects of usability but also through pedagogical ones.

Meaningful learning engages students in tackling the topic to be learnt in such a way that they create meaningful and understandable knowledge structures in accordance with goals set for learning. Meaningful learning is founded on activity and intention, reflection and self-evaluation, collaboration and interaction, construction, contextualization, and cumulative learning (Bransford, Brown \& Cocking, 2000; Löfström \& Nevgi, 2007). These form a set of criteria for selecting ICT applications and planning the teaching and learning activities where ICT applications are used.

Activity and intention. Since students take responsibility for their own learning, they set their learning goals together with a teacher and act in accordance with these goals. While this process may be facilitated by guiding students to do planning on their own or in small co-operative groups, it is worth noting that goal setting should be supported and managed by the teacher.

Reflection and self-evaluation. Students examine their own learning and develop their metacognitive skills which are necessary for planning and evaluating their own learning. Furthermore, these skills make learning a self-regulatory process in which the student becomes less dependent on the teacher.

Collaboration and interaction. Since research on collaborative interactions indicates that successful collaborative learning is facilitated by the co-regulated engagement of the group in the shared problems, students should be encouraged to take part in group activities where they support each other by discussing and sharing knowledge. The use of ICT offers several opportunities to share ideas via newsgroups, e-mail, WIKIs, a Learning Management System (LMS), and social media such as Facebook.

Construction. Since students actively build new knowledge based on their previous knowledge while learning, tailored information helps them to construct comprehendable structures.

Contextualization. Theories of situated cognition emphasise the importance of relating learning to authentic contexts, like real-life situations or simulations. This in turn presupposes that the learning setting allows for such learning experiences. For example, when using a search engine such as Google, students, should be encouraged to look for information from various sources. This enables the students to process concepts in various contexts, and thereby, extend the meanings these concepts acquire.

Cumulative learning. Since learning is cumulative, students should be supported in understanding how a new concept is related to the previous already familiar network of concepts. Learning science and developing ICT skills can be regarded as similar processes. For example, before a student learns to use an LMS, they should learn to use a word processor and a search engine.

The characteristics of a learning activity may be realized through the use of ICT applications, which could promote meaningful learning in both categories of ICT use, (A) tool applications and (B) applications for learning. Students could actively engage in learning with a word processor or presentation program and actively explore the meanings of concepts through processing information. In a laboratory, students are directly engaged in constructing their own models through measuring and presenting the data graphically. Similarly, constructing digital photos, audio recordings or spreadsheet models provides students with the opportunity to realise their perceptions, clarify their understanding of the world, and moreover, give meaning to various observations and experiences.

ICT allows children to engage with authentic, real-world situations, the Internet especially providing access to knowledge worldwide through tools such as Google Earth. Spreadsheets, databases, simula- 
tions and games allow complex, real-world situations to be modelled and analysed. In addition, ICT could support meaningful learning through facilitating communication, collaboration and cooperation; for example, working together on a laptop or interactive whiteboard, or using Web 2.o tools (see Jonassen, Howland, Marra, \& Crismond, 2007).

Motivation describes the factors within an individual which arouse, maintain and channel behaviour towards the aims of the learning activity and could be conceptualised in terms of the Self-Determination Theory (SDT) (Deci \& Ryan, 2004). Central to SDT is the concept of basic psychological needs that are assumed to be innate and universal. These needs are autonomy, competence, and relatedness (the need to belong to a group). Furthermore, the student's interest in a learning activity can be considered as an additional need. Consequently, a pedagogically usable ICT application could facilitate learning and increase the motivation of a learner. The use of an application could increase the feeling of autonomy, for example, when seeking information on the Internet. Furthermore, the use of Web 2.0 applications can promote the feeling of relatedness.

\section{Components of technical and pedagogical usability}

In Figure 1, we summarise the usability of an ICT application as a component of its usefulness. The main classification is the division into pedagogical and technical usability. Pedagogical usability is related to the adoption of ICT applications from the pedagogical point of view. The application is most likely to be adopted if teachers consider it useful or as having high pedagogical usability. In practice, teachers contemplate whether the use of the ICT application supports meaningful learning and student motivation. However, in addition to the characteristics of the ICT application itself, the cultural constraints and affordances could also have an effect on adoption as discussed in the framework of adoption categories described by Fullan (2001). In addition to internal aspects such as the pedagogical orientation of the teacher and beliefs about the usability of an ICT application, there are various external factors affecting the adoption process. These include administrative leadership and support, funding, in-service training, and collaborative partnerships with outside organisations. Technical usability is related to technical aspects of the ICT application and its adoption, such as how easy it is to learn to use and how pleasant its use is.

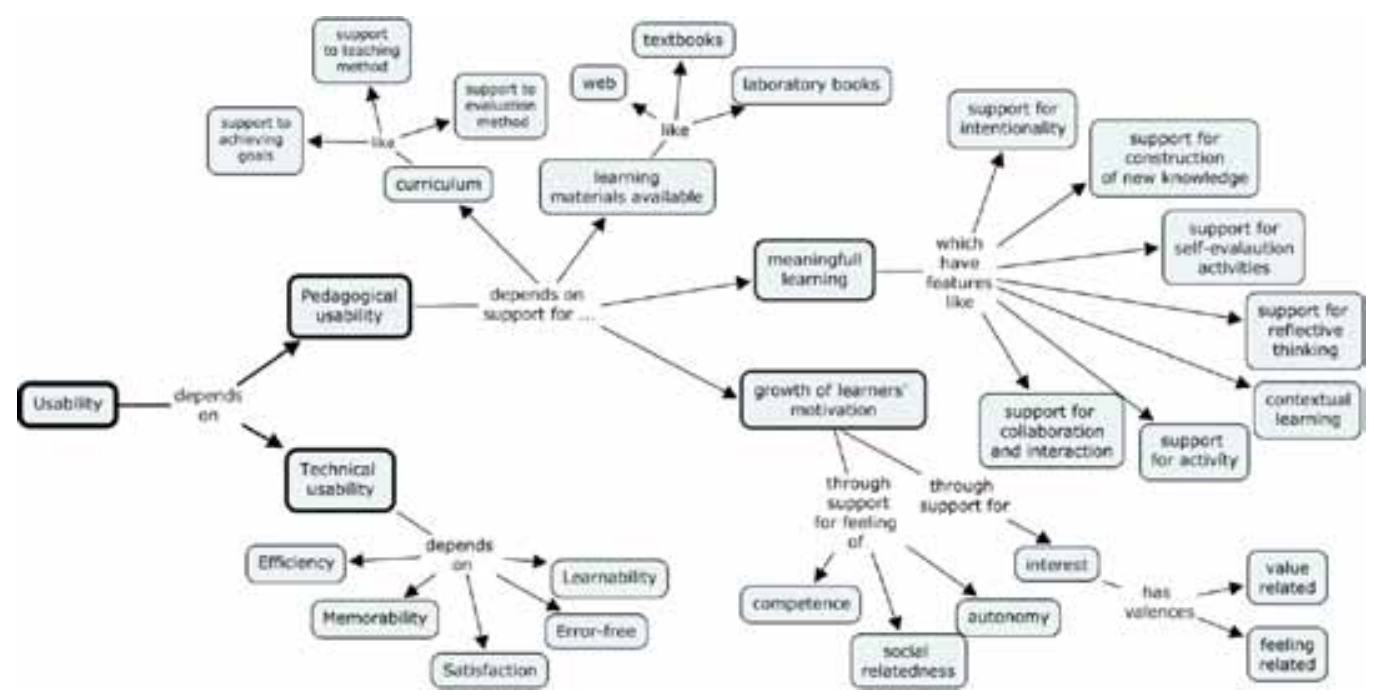

Figure 1. The usability of an ICT application approached through pedagogical and technical components 
As shown above in the educational field, the usability of an ICT application is a complex concept, so that analysis should take the users of the ICT application and their needs, the educational context with regard to the curriculum, available learning materials, and implementation in the classroom into account. We attempt to address these issues in the following discussion of needs analysis.

\section{DESIGN OF THE COURSE MODULE}

The overall aim of the course module is to help science teachers to choose and adopt ICT applications for teaching and learning science. In order to enhance their potential, the module comprises four sub-modules which approach usability from different perspectives: (1) content related and technical usability, (2) usability, especially in the case of multimedia, (3) meaningful learning issues related to usability, and (4) motivational issues related to usability. The content related usability has been included in the technical usability sub-module because content specific issues such as validity should be taken into account in using the ICT application, especially in the case of web-pages, simulations and modelling. Furthermore, students are not able to use an ICT application if the difficulty level of the content is too high. The challenge in designing the course is to take into account the complexity of usability. It is noteworthy that the aim of the course module is not to cover all possible aspects but to provide a basis for approaching usability issues. Table 1 shows the objectives of the course module.

The whole course module provides activities for further professional development in two ways. First, the underlying idea is that teachers should become aware of various components of usability. For example, teachers should acquaint themselves with technical usability and content-related issues, which can be seen to form criteria for assessing ICT applications available for science teaching and learning. Since the usability and appropriateness of a particular ICT application is in relation to the learning objectives, it is not enough to evaluate only the technical features of an ICT application as such. Teachers should become aware of the aspects in terms of which tools and applications can be discussed. However, assessing and choosing the applications to be used in the classroom are always case-specific.

Second, since usability is something relative and dependant on the aims set for learning as well as the way of teaching, teachers should be proficient in assessing and choosing ICT applications in general. Since acquiring basic knowledge is not enough, the ability to apply such knowledge in practice is needed as well. In the course module, the aim is not only to focus on basic information about usability but also to provide activities through which teachers can apply and integrate their knowledge in practice. The 'best practice examples' are to be discussed from various usability perspectives . In this way, teachers become familiar with some new technological innovations, in accordance with the wishes they stated in the survey and, even more importantly, they learn how to apply their knowledge in various situations.

In practice, the course module was composed of a selection of material, such as Power Point presentations , 'best practice examples' and a list of relevant web pages for each sub-module. The prototype of the course module was implemented in an in-service training course. The updated version of the course is available on-line (Koistinen, Krzywacki, Welzel-Breuer, \& Graf, 2010). 
Table 1. The objectives of the course module, focusing on usability of ICT applications in science education.

The overall aim of the module: a teacher is able to choose ICT applications for science education and take the technical and pedagogical usability of the application into account.

\begin{tabular}{|c|c|c|c|}
\hline $\begin{array}{l}\text { Sub module } 1 . \\
\text { Content related and } \\
\text { technical usability }\end{array}$ & $\begin{array}{l}\text { Sub module } 2 . \\
\text { Usability of multimedia }\end{array}$ & $\begin{array}{l}\text { Sub module } 3 . \\
\text { Meaningful learning } \\
\text { issues related to usability }\end{array}$ & $\begin{array}{l}\text { Sub module } 4 . \\
\text { Motivational } \\
\text { usability }\end{array}$ \\
\hline $\begin{array}{l}\text { A learner is familiar } \\
\text { with and is able to } \\
\text { take science content } \\
\text { related and technical } \\
\text { issues into account in } \\
\text { selecting an ICT } \\
\text { application for a } \\
\text { leaning activity. }\end{array}$ & $\begin{array}{l}\text { A learner is familiar with } \\
\text { and is able to take issues } \\
\text { related to usability of } \\
\text { multimedia into account } \\
\text { in selecting an ICT } \\
\text { application for a leaning } \\
\text { activity. }\end{array}$ & $\begin{array}{l}\text { A learner is familiar with } \\
\text { and is able to take } \\
\text { learning related issues } \\
\text { into account in selecting } \\
\text { an ICT application for a } \\
\text { leaning activity. }\end{array}$ & $\begin{array}{l}\text { A learner is familiar } \\
\text { with and is able to } \\
\text { take motivational } \\
\text { issues into account } \\
\text { in selecting an ICT } \\
\text { application for a } \\
\text { leaning activity. }\end{array}$ \\
\hline $\begin{array}{l}\text { The content of this } \\
\text { sub-module is } \\
\text { provided in two } \\
\text { separate parts: } \\
\text { technica/and } \\
\text { content-related } \\
\text { usability. } \\
\text { A learner will } \\
\text { - acquaint him or } \\
\text { herself with issues } \\
\text { related to technical- } \\
\text { and content-related } \\
\text { usability on the basis } \\
\text { of research-based } \\
\text { knowledge and } \\
\text { literacy. Usability will } \\
\text { be introduced } \\
\text { through some main } \\
\text { concepts regarding } \\
\text { these two notions. } \\
\text {-apply such } \\
\text { knowledge in } \\
\text { assessing some } \\
\text { examples ('best } \\
\text { practice examples' or } \\
\text { the learner's own } \\
\text { examples). }\end{array}$ & $\begin{array}{l}\text { A learner will } \\
\text { - acquaint him or herself } \\
\text { with theoretical aspects } \\
\text { of learning with media } \\
\text { as part of teaching and } \\
\text { learning science. In } \\
\text { particular, a learner will } \\
\text { be able to discuss } \\
\text { learning theories specific } \\
\text { to the use of media, (like } \\
\text { cognitive load, dual } \\
\text { channel) } \\
\text { - apply such knowledge } \\
\text { in assessing some } \\
\text { examples ('best practice } \\
\text { examples or the learner's } \\
\text { own examples). }\end{array}$ & $\begin{array}{l}\text { A learner will } \\
\text { - acquaint him or herself } \\
\text { with theoretical aspects } \\
\text { of the learning process } \\
\text { with ICT applications, } \\
\text { student activity and } \\
\text { intentions, student } \\
\text { knowledge construction, } \\
\text { student collaboration } \\
\text { and interaction, student } \\
\text { self-evaluation and } \\
\text { reflection, and moreover, } \\
\text { diagnostic and formative } \\
\text { evaluation as well as } \\
\text { contextualisation of the } \\
\text { learning environment } \\
\text { science teaching and } \\
\text { learning ('best practice } \\
\text { examples'). }\end{array}$ & $\begin{array}{l}\text { A learner will } \\
\text { - acquaint him or } \\
\text { herself with } \\
\text { theoretical aspects } \\
\text { of motivation, for } \\
\text { example, with } \\
\text { intrinsic and } \\
\text { extrinsic } \\
\text { motivation. } \\
\text { In addition, a } \\
\text { learner will get to } \\
\text { know about basic } \\
\text { psychological needs: } \\
\text { the need for } \\
\text { autonomy, } \\
\text { competence and } \\
\text { social relatedness, } \\
\text { and issues that } \\
\text { make the topic } \\
\text { interesting } \\
\text { - learn how to } \\
\text { evaluate motivation } \\
\text { in an activity by an } \\
\text { inventory and } \\
\text { include motivating } \\
\text { features in a } \\
\text { learning activity. }\end{array}$ \\
\hline
\end{tabular}




\section{Discussion}

We have described the design of a course module intended to support teachers in improving their potential as users of ICT applications in science education. The design-based research (DBR) approach has provided a framework for this process. In the design of the course module, different aspects of usability have been elaborated on to clarify the complex notion of usability, especially in the educational field, in order to enhance professional readiness for versatile use of ICT applications. In general, the usability of an ICT application refers to how easy it is to achieve the learning aims. Distinguishing the pedagogical and technical usability is supported by the various educational aspects evident in the research literature (Nokelainen, 2005; Hadjerrouit, 2010; Squires \& Preece, 1996; Squires \& Preece, 1999; Tergan, 1998). In addition, the results of the survey of the project provide another argument in favour of this approach. According to the survey, the concept of usability should be introduced to teachers not only through technical but also through pedagogical aspects of usability. The idea behind the design of the course module is to enhance the readiness of science teachers in applying ICT applications by discussing both technical and pedagogical usability, the components of which could be used to support the planning of teaching activities.

Here, we have approached the concept of usability from the technical and pedagogical point of view, arguing that both aspects should be introduced to science teachers. Technical usability refers to the quality of ICT application use, i.e., how an ICT application is convenient, practicable, and usable for a learner (see Buzzetto-More, 2007; Nielsen, 2000). Pedagogical usability has been approached by analysing what kind of learning and development of motivation the use of the ICT application creates. Learning that aids in achieving the set aims is characterised as active and intentional, reflective, constructive, collaborative and interactive and contextual, as well as cumulative. It is worthwhile thinking about each of these aspects to consider how ICT might make learning meaningful (Jonassen et al., 2007). From the point of view of motivation, the use of ICT applications should meet the need for autonomy, competence and relatedness (Deci \& Ryan, 2004). While the use of such applications does not however automatically make learning meaningful and motivating, it does offer potential. For example, the use of a web browser supports intentions and satisfies the need for autonomy if the teacher and students plan the learning activity together and students are supported in making the aims of the curriculum their own. Moreover, the activity should be scaffolded by the teacher. When searching the web together, students are likely to collaborate in meeting the need for relatedness.

While designing the course module, we encountered several challenges in supporting the teachers in adopting ICT applications into their science teaching. Even if a teacher is skilful in using ICT in general, for example, for personal purposes, the pedagogical perspective needs a different orientation. Furthermore, it is not enough to pay attention to the quantity of the use of ICT applications in science education. The quality of ICT use can be seen as more important. Teachers need to gain some meta-level skills and knowledge about the use of ICT applications for educational purposes, which is why the course module introduces the concept of usability. In this case, usability refers to achieving the aims set for the activity in which the application is used. We have thus learned that the usability of ICT applications is a complex concept referring to several issues, such as the application itself, the way applications are used, users such as science teachers and their competence, beliefs, and the context in which the application is applied. In addition, national-level strategies, the framework curriculum, the pre-service and in-service teacher education available and collaboration between designers of the applications and teachers influence the ways ICT is used in science education. Therefore, in planning a teaching situation a teacher should make several decisions about teaching approaches, learning materials and the use of ICT applications. Teachers should know and apply such knowledge in selecting and using ICT applications in their teaching (Wang, 2008).

Based on the previous analysis on the adoption of innovations (Rogers, 2003) discussion and sharing of ideas are needed to assist adoption in an in-service course. The course module was prepared to address these demands. The course module aims to provide: (1) a series of interactive lectures including 
information on the sub-module topic and discussions; (2) experience with planning, implementing and evaluating reflecting on a teaching experiment in the field of the course module; (3) collaboration at school level requiring the participation of at least two school teachers; (4) collaborative planning of teaching experiments including the use of ICT applications, (5) follow-up meetings at which experiences from teaching experiments which have been mplemented are discussed and reflected on and results shared with other teachers, and (6) open discussion of student feedback after teaching experiments. The course has been implemented once and empirical data consisting of teachers' views of usability and the adoption of this concept has been collected. The results of piloting the course module will be published separately.

It is widely agreed that the use of ICT applications opens up new opportunities for teaching and learning science. Consequently, teachers need to commit themselves to professional development in order to be able to benefit from new opportunities and perhaps renew their pedagogical views of science education. We do not claim that the way of teaching and learning science should be completely changed. The challenge is to influence the beliefs teachers have about the use of ICT applications. Thus, the critical point is whether teachers integrate the ICT applications in their classroom activities. The characteristics of meaningful learning in the context of ICT use is analysed in the course module in order to support this integration. Moreover, the motivation to learn science is approached through the three basic notions stated by Deci and Ryan (2004). The idea is to provide a solid basis for professional readiness, including some knowledge and skills. In addition to strengthening their feeling of competence, teachers have an active role in the course and are expected to cooperate with each other.

\section{ACKNOWLEDGEMENTS}

This paper has been supported by the project 141767-LLP-1-2008-1-DE-COMENIUS-CMP.

\section{REFERENCES}

Alexander, B. (2006). Web 2.0: A new wave of innovation for teaching and learning? EDUCAUSE, Review,41(2), 33-44.

Bell, P., Hoadley, C.M., \& Linn, M.C. (2004). Design-based research. In M.C. Linn, E.A. Davis, \& P. Bell (Eds.), Internet environments for science education (pp. 73-88). Mahwah, New Jersey, Lawrence Erlbaum Associates.

Bransford, J.D., \& Donovan, S.M. (2005). How Students Learn Science in the Classroom. Washington, D.C.: National Academies Press.

Buzzetto-More, N.A. (2007). Advanced Principles of Effective e-Learning. Santa Rosa: Informing Science Press.

Deci, E.L., \& Ryan, R.M. (2004). Handbook of Self-determination Research. Rochester, NY: The University of Rochester Press.

Fullan, M. 2001. The New Meaning of Educational Change, 3rd ed. New York and London: Teachers. College Press.

Hadjerrouit, S. (2010). An Empirical Evaluation of Technical and Pedagogical Usability Criteria for Web-Based Learning Resources with Middle School Students. In D. Gibson \& B. Dodge (Eds.), Proceedings of Society for Information Technology \& Teacher Education International Conference 2010 (pp. 2231-2238). Chesapeake, VA: AACE

Hayes, D.N.A. (2007). ICT and learning: Lessons from Australian classrooms. Computers \& Education, 49(2), 385-395.

Jonassen, D.H., Howland, J., Marra, R.M., \& Crismond, D P. (2007). Meaningful Learning with Technology ( $3^{\text {rd }}$ ed.). Upper Saddle River, New Jersey: Pearson Merrill Prentice Hall.

Juuti, K., \& Lavonen, J. (2006). Design-Based Research in Science Education. Nordina 3(1), 54-68. 
Koistinen, L., Krzywacki, H., Welzel-Breuer, M., \& Graf, S. (2010). Cat4u-A European Teacher Training Course for Science Teachers: Handbook for a teacher training course. Paisii Hilendarski: Plovdiv University Press. Retrieved June 14, 2011, from http://cat.upatras.gr/en/taxonomy/ term $/ 90$

Lavonen, J., Juuti, K., Aksela, M., \& Meisalo, V. (2006). A professional development project for improving the use of information and communication technologies in science teaching. Technology, Pedagogy and Education, 15(2) 159-174.

Linn, M.C., \& Eylon, B.-S. (2006). Science Education: Integrating Views of Learning and Instruction. In P. A. Alexander \& P. H. Winne (Eds.), Handbook of Educational Psychology ( $2^{\text {nd }}$ Ed., pp. 511544). Mahwah, NJ: Lawrence Erlbaum Associates.

Löfström, E., \& Nevgi, A. (2007). From strategic planning to meaningful learning: Diverse perspectives on the development of web-based teaching and learning in higher education. British Journal of Educational Technology, 38(2), 312-324.

McFarlane, A., \& Sakellariou, S. (2002) The Role of ICT in Science Education, Cambridge Journal of Education, 32(2), 221-232.

Nielsen, J. (1993). Usability Engineerings. Boston (MS.): Academic press.

Nielsen, J. (2000). Designing Web Usability: The Practice of Simplicity. New York: Riders.

Nokelainen, P. (2005). The technical and pedagogical usability criteria for digital learning material. In P. Kommers \& G. Richards (Eds.), Proceedings of World Conference on Educational Multimedia, Hypermedia and Telecommunications 2005 (pp. 1011-1016). Chesapeake, VA: AACE.

OECD (2004). Completing the Foundation for Lifelong Learning: An OECD Survey of Upper Secondary Schools. Paris: OECD.

OECD. (2006). Are students ready for a technology-rich world?: What PISA studies tell us (No. 54931). Paris: Programme for International Student Assessment.

Osborne, J., \& Hennessy, S. (2003). Literature Review in Science Education and the Role of ICT: Promise, Problems and Future Directions. Bristol: Futurelab.

Rogers, E.M. (2003). Diffusion of innovations. (5th ed.) New York: Free Press.

Squires, D., \& Preece, J. (1996). Usability and learning: Evaluating the potential of educational software. Computers \& Education, $27(1), 15-22$.

Squires, D., \& Preece, J. (1999). Predicting Quality in Educational Software: Evaluating for learning, usability and synergy between them. Interacting with Computers 11, 467-483.

Tergan, S-O. (1998). Checklists for the evaluation of educational software. Critical review and prosects. Innovations in Education and Training International, 35(1), 9-20.

Wang, Q. (2008). A generic model for guiding the integration of ICT into teaching and learning. Innovations in Education and Teaching International, 45(4), 411-419.

Watson, D.M. (2001). Pedagogy before Technology: Re-thinking the Relationship between ICT and Teaching. Education and Information Technologies 6(4), 251-266.

Webb, M. (2002). Pedagogical reasoning: Issues and solutions for the Teaching and learning of ICT in Secondary School. Education and Information Technologies 7(3), 237-255.

Welzel-Breuer, M., Graf, S.,Sanchez, E., Fontanieu, V., Stadler, H., Raykova, Z., Erb, R., Lavonen, J., \& Ioannidis, G. (2010): Application of Computer Aided Learning Environments in Schools of Six European Countries. In: Contemporary Science Education Research. Scientific Literacy and Social Aspects of Science. A collection of papers presented at ESERA 2009 Conference. Edited by Gültekin Cakmakci and Mehmet Fatih Tasar. ESERA. 317-326. http://www.naturfagsenteret.no/ esera/conference.html 